\title{
TRANSFORMATION OF A HEALTH SCIENCES POSTGRADUATE POPULATION (2008-2017) AT A HIGHER EDUCATION INSTITUTION IN SOUTH AFRICA: HAS THIS OCCURRED?
}

\author{
M. Meela* \\ Health Sciences Research Office, School of Anatomical Sciences \\ e-mail: Moraba.Meela@wits.ac.za \\ E. Libhaber* \\ Health Sciences Research Office, School of Clinical Medicine \\ e-mail: Elena.Libhaber@wits.ac.za / https://orcid.org/0000-0002-7043-4002

\section{B. Kramer*} \\ School of Anatomical Sciences \\ e-mail: Beverley.Kramer@wits.ac.za / https://orcid.org/0000-0002-8779-7491
}

*Faculty of Health Sciences, University of the Witwatersrand

Johannesburg, South Africa

\section{ABSTRACT}

Despite efforts to prioritise transformation of the previously disadvantaged population, inequalities created by the Apartheid system persist in the South African higher education system. This study assessed transformation in relation to population affinity and gender of first-time enrolments of Health Sciences (HS) postgraduate students at the University of the Witwatersrand (Wits), Johannesburg. A retrospective study of the Wits HS postgraduate student database was used for this assessment. The probability of a postgraduate student being Black African increased by 7.5 per cent per year [OR: 1.075, 95\% Cl (1.052-1.099), $\mathrm{p}<0.001$ ] over the period 2008-2017 and of being female, increased by 5.6 per cent per year [OR: 1.056, 95\% Cl $(1.033-1.081), p<0.001]$. While transformation has occurred, Black African females are still under-represented. The transformation of the postgraduate student body as observed in this study is of importance to other countries struggling with racial and gender equity in the health workforce.

Keywords: transformation, population affinity, gender, postgraduate students, higher education system

\section{INTRODUCTION}

Apartheid in South Africa was a system which segregated local society in order to advance and protect the interest of one population group, mainly the White population (Volmink 2008). This system created disparities in all facets of society including the higher education system (Badat 
2004; Breetzke and Hedding 2018; Bunting 2006). Twenty six years after the inception of the new democracy (1994), South Africa is still struggling to eradicate the imbalances caused by the system of apartheid.

The South African higher education system has been marred by segregation from as early as 1951, as South Africa only had one college for Black individuals, but eight colleges for Whites (Robus and Macleod 2006). Subsequently, higher education institutions were designated "Black only" or "White only" (Robus and Macleod 2006). This resulted in the provision of unequal higher education as "White only" institutions were adequately resourced but "Black only" institutions were greatly limited in their resources (Breetzke and Hedding 2018; Bunting 2006). However, two of the "White only" universities, namely the University of the Witwatersrand and the University of Cape Town, were regarded as "open universities" as they admitted Black students (Robus and Macleod 2006; Murray 2007). The term "Black" here refers collectively to African, Coloured and Indian individuals who were previously disadvantaged during the apartheid era (Ramrathan 2016). Furthermore, the Second World War prompted the latter two "open universities" to admit additional Black students into their Medical Schools, as international medical training for the Black population became impossible (Murray 2007; Digby 2013). However, training of Black medical students and White medical students was still separated. Black medical students, while receiving teaching with their White counterparts, were trained separately in clinical skills at designated "Non-European" Hospitals (Murray 2007). In addition, in 1959 the White Nationalist government promulgated a law to prohibit "open universities" from enrolling Black students (Robus and Macleod 2006; Murray 2007). Accordingly, the University of the Witwatersrand imposed a quota system for admitting Black students on its Medical School and thus reduced the number of Black student enrolments in medicine, while the dental, physiotherapy and occupational therapy courses were no longer allowed to admit Black students (Murray 2007; Tobias 2005).

Thus prior to the end of Apartheid in South Africa, the numbers of black doctors working in the community were low (Shung-King et al. 2018). This limitation in the training of Black doctors had a major impact on the delivery of care to communities. The Apartheid period in South Africa is reminiscent of the difficulties experienced in the United States of America (USA) where "people of color" (Noonan, Lindong, and Jaitley 2013) were historically underrepresented in all the health professions. In the 1970s in the USA, affirmative action programmes were introduced (Keith et al. 1985). These programmes aimed at increasing the number of physicians from minority groups in order to improve health care to the poor. Yet even by 2013, although "people of color" accounted for more than 25 per cent of the population, they comprised only 10 per cent of health professionals (Noonan, Lindong, and Jaitley 2013). 
The under-representation of minority groups in the health professions in the USA has been extensively dealt with in the Sullivan Commission report (Sullivan 2004) and the Institute of Medicine "Unequal Treatment" report (Smedley, Stith, and Nelson 2003). Smith et al. (2009) maintains that "racial and ethnic minority" health professionals generally are more likely to serve medically underserved communities than their White counterparts. They further suggest that pipeline programmes are important for supporting the development of under-represented minorities. As an example, the University of Washington set up a Native American Center of Excellence, which provided a pipeline for American Indian/Alaskan Native applicants (Acosta and Olsen 2006).

An understanding of cultural factors and economics often play a large role in the quality of health care which a health professional may impart to a patient (Nelson 2002). Thus increasing the number of Black health professionals, both female and male, is of great significance for South Africa where the majority of the population is made up of the former under-represented "minority". Increasing the number of Black health professionals may reduce the disparities in health care, currently being experienced. In order to attract more females, particularly black females into the health professions in South Africa, the culture of the work environment (Westring et al. 2012) and the issue of gender-stereotyping (Alwazzan and Rees 2016) must be reformed.

In South Africa transformation of the higher education system has been made a national imperative (Cloete and Moja 2005). However, twenty six years later, South Africa's higher education system still does not reflect the demographics of South African society despite efforts such as the implementation of the White Paper 3 (DoE 1997) by the current government, to redress the inequalities created by apartheid (Norris 2001; Soudien 2009; Ramrathan 2016; DoE 1997). Black African students (both female and male) are still said to be under-represented in higher education institutions (Badat 2010; Seabi et al. 2014). There is a need to ensure demographic representation in the higher education system as South Africa has a diverse population where Black Africans represent the majority $(80.9 \%)$ of the population, with Coloured (8.8\%), Indian (2.5\%) and White $(7.8 \%)$ groups contributing the remainder (Stats SA Mid Year population estimates 2018). The under-representation of Black African students is said to be alarming at postgraduate level particularly in historically white institutions (Seabi et al. 2014).

Females in general were excluded from higher education as apartheid created a White and male dominated system (Badat 2004; Mouton 2003). Black females were particularly affected, as they suffered from both apartheid policies and from genderism (Wing and De Carvalho 1995). Although the new South African democratic government has made efforts to address the 
inequalities in the higher education system, the under-representation of Black females still exists (Ramrathan 2016; Ramohai 2019). Therefore, the goal of transformation in higher education seems far from being realised.

"Transformation is a form of change of one form into another" (Van Niekerk 1998). The aim of transformation in society is to have an improved, just and equitable society (Waghid 2002). Transformation of the higher education system is a multifaceted endeavour which involves the curriculum, epistemology, demographics of staff and students, and the institutional milieu and ethos (Badat 2010; Bazana and Mogotsi 2017; SACHE 2016). Thus, the transformation endeavour may differ from one institution to another, as institutions have their own unique issues that require a contextual approach (Ramohai 2019; SACHE 2016). Breetzke and Hedding (2018) define transformation from the South African higher education perspective as "undoing the historical injustices that the majority of the Black African population suffered in terms of access, availability and representation in the higher education sector of the country".

Wits University defines transformation as "a process of negotiated organisational change that breaks decisively with past discrimination practices in order to create an environment where the full potential of everyone is realised and where diversity, both social and intellectual, is respected and valued and where it is central to the achievement of the institution's goals" (University of the Witwatersrand Transformation Transformation Office 2017). We subscribe to Wits University's vision which is "where the full potential of everyone is realised and where diversity, both social and intellectual, is respected and valued". Furthermore, we believe that transformation in higher education is a complex process which includes equality issues and the effectiveness of the higher education system, social cohesion and the eradication of discrimination, curriculum change, management change and Africanization of teaching and learning (Du Preez, Simmonds, and Verhoef 2016; Luvalo 2019). Transformation in institutions of higher learning should also entail "epistemological change and access, policy reform and socio-political redress, but it should be ethical" (Du Preez, Simmonds, and Chetty 2017). Overall, transformation of higher education in South Africa should challenge issues that have previously polarized the South African society (Francis and Hemson 2010).

Wits is located in Johannesburg, the largest metropolitan area in South Africa, with a sizeable migratory population from the local surrounding areas and also from other African countries, who come to work on the gold mines and in other industries (Collinson, Tollman, and Kahn 2007; Turok and Borel-Saladin 2014). The Wits Faculty of Health Sciences is ranked in the top 100 medical schools in the world (Times Higher Education Ranking 2019). Despite it being an internationally renowned university, Wits University and the Wits Faculty of Health Sciences (FHS) are still grappling with the challenge of equity redress of the student body. 
Effort has been made by Wits in addressing the demographic profile of undergraduate students (Wits University Senior Executive Team 2015). However, little is known about the demographic profile of postgraduate students. This is of concern, as postgraduate students are a potential pool for the future academic workforce and in health sciences particularly, for the health workforce. A transformed postgraduate cohort would augur well for a future diversified academic workforce. Health Sciences education and healthcare in South Africa were fragmented by the apartheid system (Coovadia et al. 2009; Thackwell et al. 2016). The new South African democratic administration identified the health sector as a major role player in its approach to combating poverty and discrimination, and in nation building (Mostert-Wentzel, Frantz, and Rooijen 2013). However, the health sector in South Africa has been dominated by White males particularly at senior levels (Thackwell et al. 2016). Therefore, it is essential to build capacity which will in future contribute to strengthening and diversifying the health sciences and healthcare workforce which will serve the needs of all South Africans.

This study has thus focused on investigating transformation of the postgraduate cohort of students, who would be a pool for the health sciences workforce. The aim of this study was to assess transformation in relation to population affinity and gender of first-time enrolments of postgraduate students in the Wits FHS over the period 2008-2017.

\section{METHODS}

\section{Ethics}

Permission to use the dataset was obtained from the Office of the Deputy Registrar at the Wits University, Johannesburg, South Africa. Ethics approval to conduct this study was obtained from the Wits Human Research Ethics Committee (Medical) [Clearance certificate number: M180262].

\section{Data source}

Data for this study was obtained from the Business Intelligence Services, Wits University. The Business Intelligence Services manages all student data for the institution and updates records of Wits postgraduate students on an annual basis. The database was recorded as "Postgraduate Cohort Data".

\section{Study population}

All students registered for a postgraduate degree in the Wits Faculty of Health Sciences (FHS) between 2008 and 2017 were considered for this study. Postgraduate students registered in the Faculty of Science but supervised in the Wits FHS were also included. The binary male /female gender was used in this study as the Wits Business Intelligence Services (BIS) was set up in 
this manner. Population affinity was disaggregated into Black African, Chinese, Coloured, Indian and White as these terms are used in post-apartheid South Africa (Lehohla 2011; Harris 2017).

Non-South African postgraduate students were excluded as the study focused on transformation from a South African perspective as guided by the White Paper 3 of the current government (DoE 1997).

\section{Study design}

A retrospective review of the postgraduate students database of the Wits FHS was used to assess transformation with respect to population affinity and gender of postgraduate students over a ten year period (2008-2017). The variables were extracted from the database and transferred to an excel worksheet. The following variables were considered: Date of registration, gender, population affinity, postgraduate degree for which registered (Master's by coursework - MC, Master's by research (MR) and $\mathrm{PhD})$. MC consists of coursework and research while the MR is full time research. The duration of an enrolment in the MC and MR are different, as most MC degrees are 4 years and the MR degree is 2 years in duration. It is mandatory for medical registrars who are specialising and training in Health Sciences Faculties in South Africa to undertake a MC degree. In addition, some students from other clinical disciplines such as Pharmacy and Occupational Therapy for example, may also be included in the Master's by coursework.

\section{Statistical analysis}

Analyses were conducted using Excel (Microsoft 2016) and Stata version 14.2 (StataCorp, College Station, TX). The 5 per cent level of statistical significance was used throughout.

Data were presented as frequencies and percentages. A Chi-square test was used to compare postgraduate student first-time enrolments proportions in 2008 with 2017.

For analysis purposes, the Chinese, Coloured and Indian students were grouped together as "Other" as their numbers were consistently small. Logistic regression models were fitted to investigate the trends in the proportions of first-time enrolments of Black African (versus White and "Other") and female (versus male) postgraduate students, adjusting for degree type. The ten year period (2008-2017) was divided into two five year periods to test for interactions.

\section{RESULTS}

\section{Enrolments}

Of the total 5285 first-time enrolments in the Wits FHS, 4170 were postgraduate students of South African origin (Figure 1) with enrolments of approximately 400 occurring per annum. 
Nineteen of the 4170 South African postgraduate students were registered in the Faculty of Science, but were undertaking studies in the FHS with FHS supervisors and are thus included in the data.

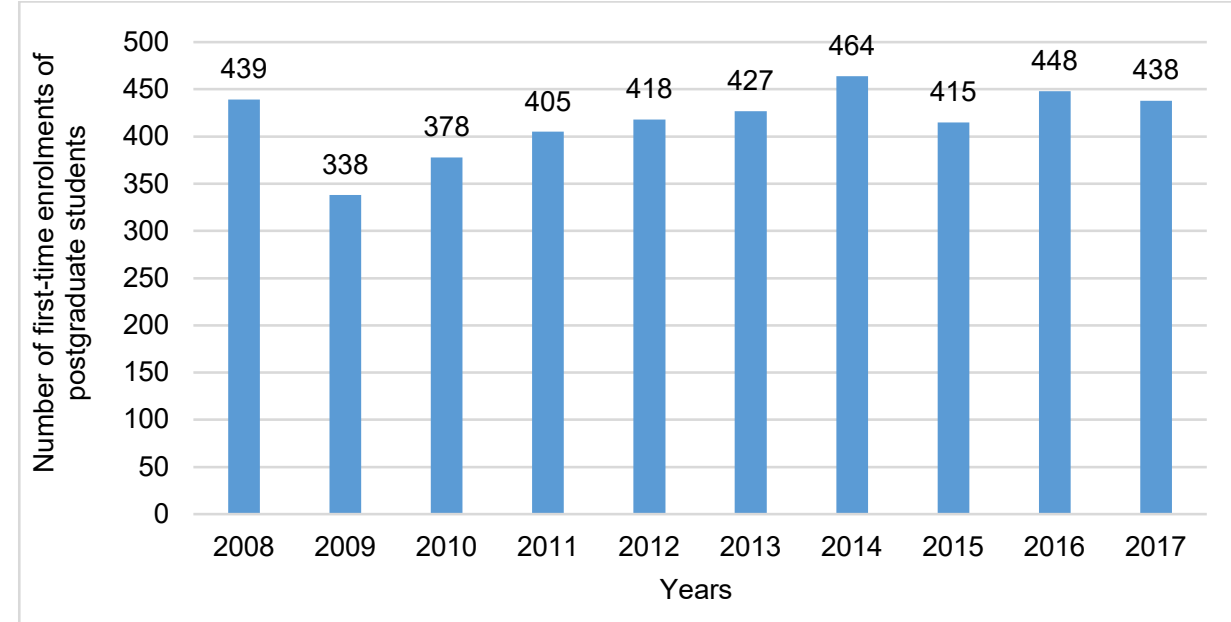

Figure 1: Wits FHS overall numbers of first-time enrolments of South African postgraduate students over the period 2008-2017

\section{Enrolments according to population affinity}

Black African postgraduate enrolments increased steadily over the period 2008-2017 (Figure 2). White students enrolments decreased between the years 2008 and 2017 while the group designated "Other" increased slightly compared with Black Africans $(\mathrm{p}=0.028)$.

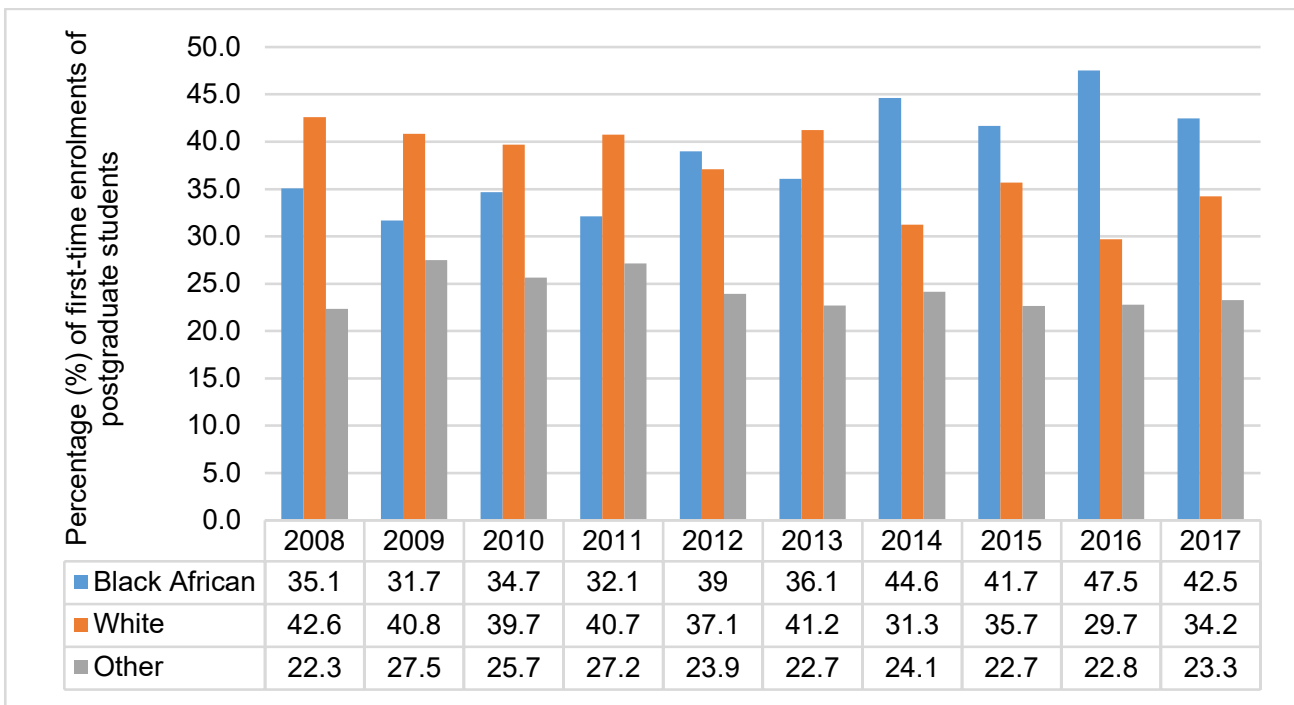

Figure 2: Wits FHS first-time enrolments of South African postgraduate students according to their population affinity (Black African, White and "Other") over the period 2008-2017 


\section{Enrolments according to gender}

Generally there were more female $(n=2738)$ than male $(n=1432)$ first-time enrolments over the period 2008-2017. Furthermore, a statistically significant increase in the percentage of females occurred between the years 2008 and 2017 ( $\mathrm{p}=0.0009$; Figure 3).

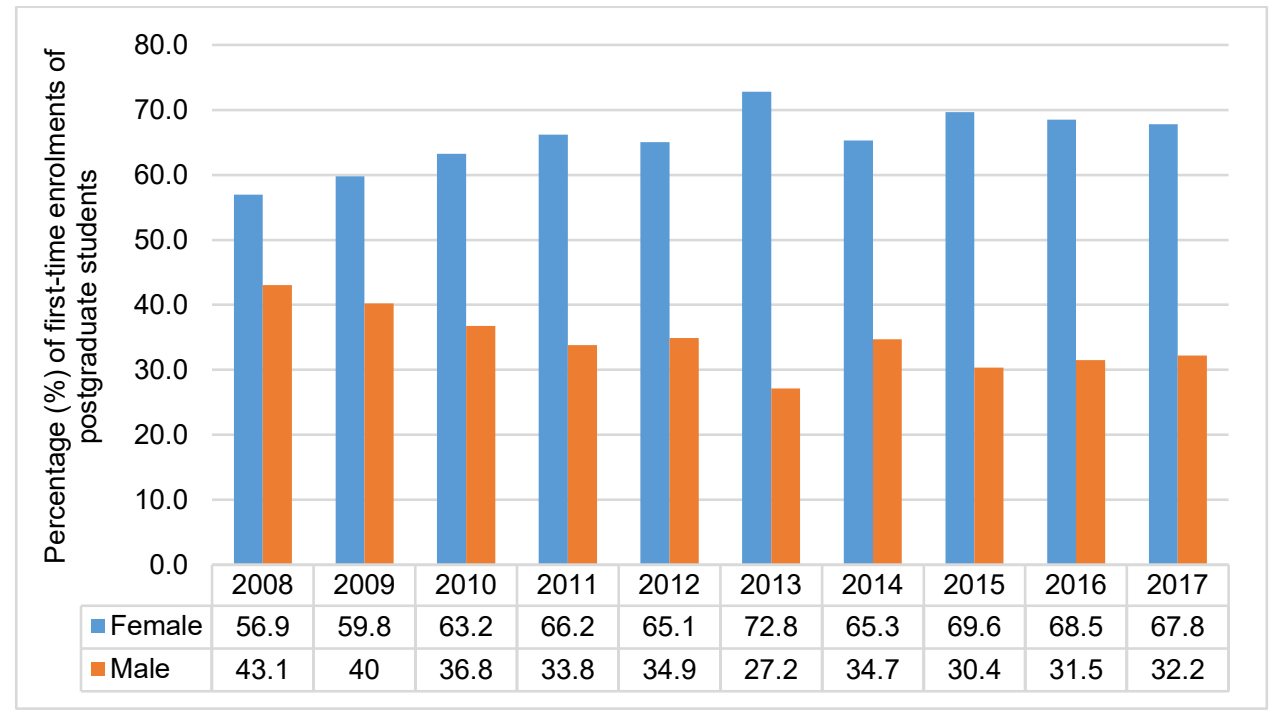

Figure 3: Wits FHS first-time enrolments of South African postgraduate students according to their gender over the period 2008-2017

\section{Enrolments according to degree types}

The degree types (Masters by coursework and research report [MC], Masters by dissertation [MR] or Doctor of Philosophy [PhD]) of first-time enrolments were analysed in relation to population affinity and gender.

More females than males accounted for first-time enrolments in the MC degree between 2008 and $2017(\mathrm{p}=0.015$; Figure 4).

While first-time enrolments of Black African students in the MR degree fluctuated between 2008-2017, White student enrolments in this degree type decreased significantly from 52.1 per cent in 2008 to 32.9 per cent in 2017 ( $p=0.02$; Figure 5). The percentage of registration of females and males remained similar $(\mathrm{p}=0.42)$ when 2008 and 2017 were compared.

The percentages of Black African and "Other" students enrolled for the $\mathrm{PhD}$ also fluctuated over the period 2008-2017 (Figure 6). There was no statistically significant difference between Black Africans, Whites and "Other" ( $p=0.93)$ enrolments over this period of time. More female students registered for the first time each year for the $\mathrm{PhD}$ than males between the years 2008 and 2017. The percentage of females enrolled for the $\mathrm{PhD}$ increased between 2008 and 2017 by 18 per cent $(p=0.047)$. 


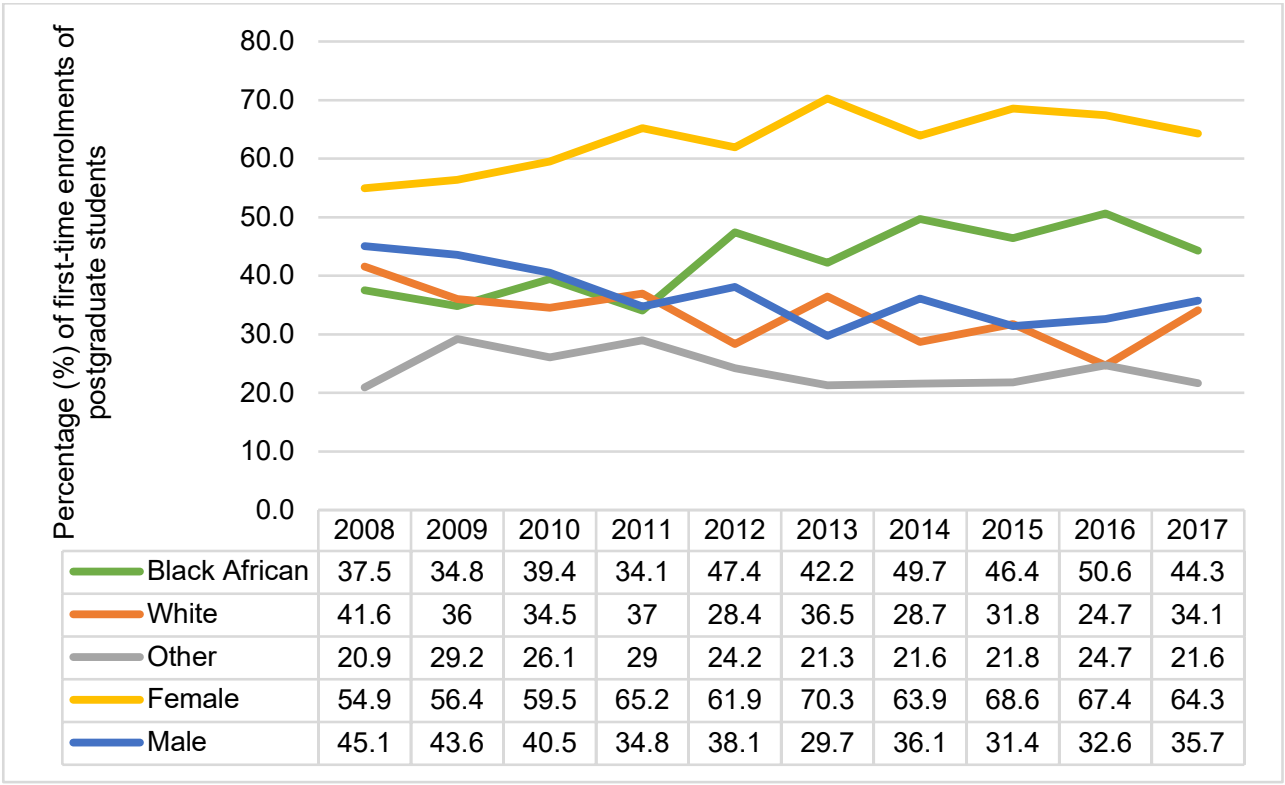

Figure 4: Wits FHS first-time South African postgraduate students enrolments for Masters by coursework and research report (MC) according to their population affinity and gender over the period 2008-2017

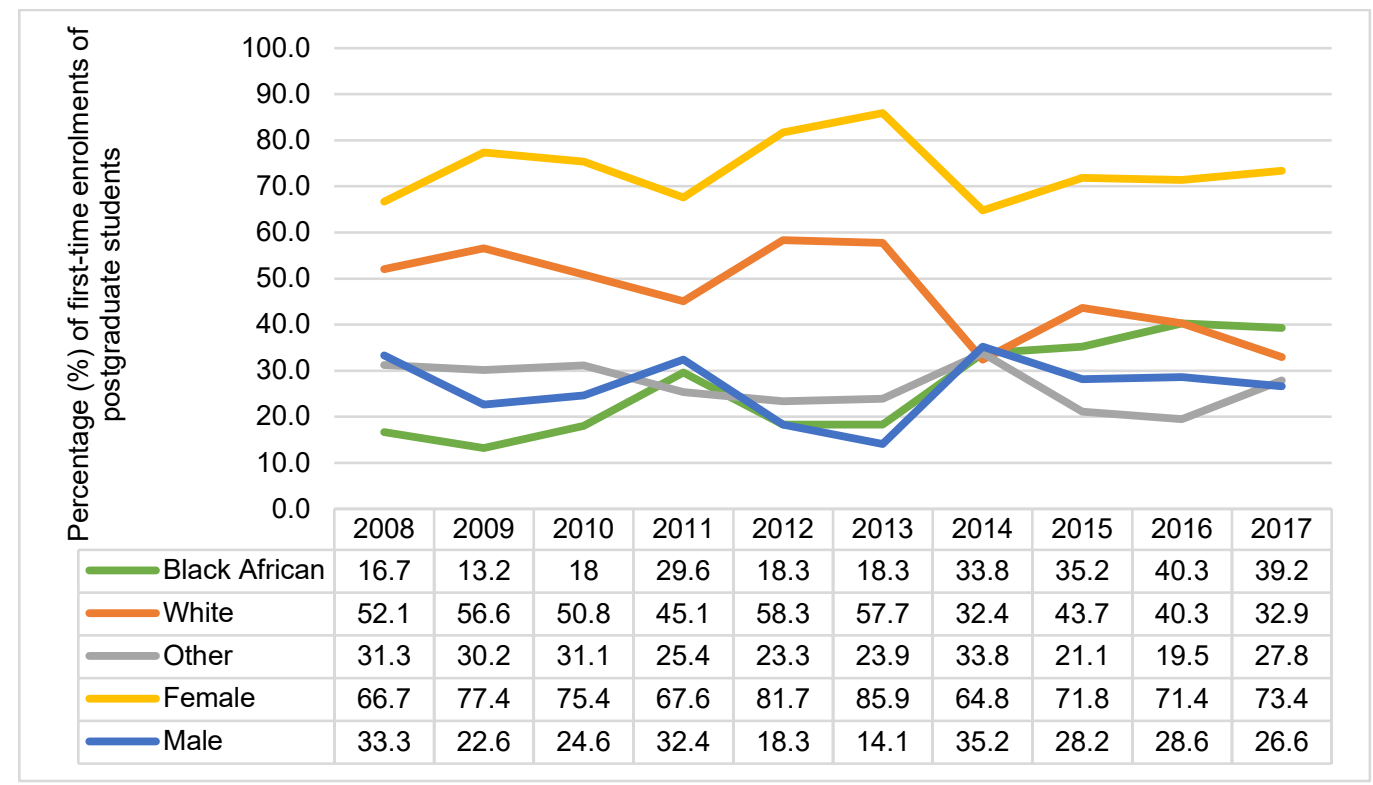

Figure 5: Wits FHS first-time South African postgraduate students enrolments for Masters by dissertation (MR) according to their population affinity and gender over the period 2008-2017

\section{Trend analysis of enrolment according to population affinity, gender and degree type}

A trend analysis was conducted to determine changes over the 10 year period. The probability of a postgraduate student being Black African increased by approximately 7.5 per cent per year [OR: 1.075, 95\% CI (1.052-1.099), $\mathrm{p}<0.001]$. For female students, the probability of being Black African was less than for males. By degree type, the probability of a student being Black 
African was less for the MR and PhD degrees, than for the MC. Therefore, Black African students predominated in registration for the $\mathrm{MC}(\mathrm{p}<0.001$; Table 1$)$.

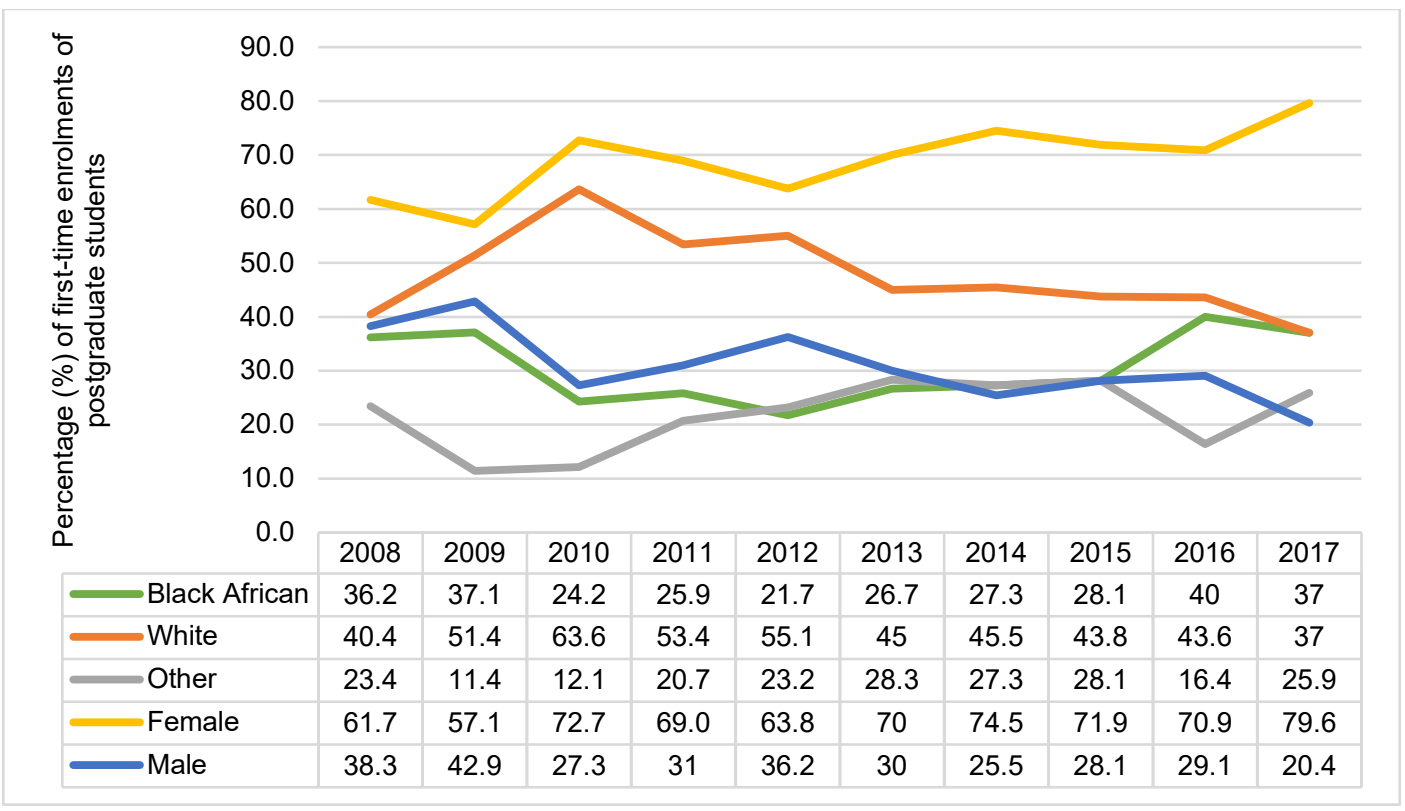

Figure 6: Wits FHS first-time South African postgraduate student enrolments for PhD according to their population affinity and gender over the period 2008-2017

Table 1: Trends of Wits FHS Black African (versus White and "Other") first-time enrolments of postgraduate students according to their gender and degree over the period 2008-2017

\begin{tabular}{|l|l|c|c|c|}
\hline Factor & Level & Odd ratio (OR) & $\mathbf{9 5 \%}$ Cl & P-value \\
\hline Year & Per unit increase & 1.075 & $1.052 ; 1.099$ & $<0.001$ \\
\hline Gender & Male & 1 & Reference & $<0.001$ \\
& Female & 0.74 & $0.65 ; 0.85$ & \\
\hline Degree Type & MC & 1 & Reference & $<0.001$ \\
& MR & 0.50 & $0.42 ; 0.61$ & \\
& PhD & 0.57 & $0.46 ; 0.69$ & \\
\hline
\end{tabular}

$\mathrm{Cl}$ - Confidence Interval, MC - Masters by coursework and research report, MR - Masters by dissertation

Over the period under investigation, the probability of a postgraduate student being female increased by approximately 5.6 per cent per year [OR: 1.056, 95\% CI $(1.033-1.081), \mathrm{p}<0.001]$. For Black African students, the probability of being female was less than for the White and "Other" groups. Therefore, a Black African postgraduate student was less likely to be female than a White or "Other" student. By degree type, the probability of a student being a female was higher for the $\mathrm{MR}$ and $\mathrm{PhD}$ than for the $\mathrm{MC}(\mathrm{p}<0.001$; Table 2$)$.

Table 2: Trends of Wits FHS first-time enrolments of female (versus male) postgraduate students according to their population affinity and degree over the period 2008-2017

\begin{tabular}{|l|l|c|c|c|}
\hline Factor & Level & Odd ratio (OR) & 95\% Cl & P-value \\
\hline Year & Per unit increase & 1.056 & $1.033 ; 1.081$ & $<0.001$ \\
\hline Population affinity & Black African & 1 & Reference & $<0.001$ \\
\hline
\end{tabular}




\begin{tabular}{|l|l|c|c|c|}
\hline Factor & Level & Odd ratio (OR) & $\mathbf{9 5 \%} \mathbf{~ C l}$ & P-value \\
\hline & White & 1.40 & $1.21 ; 1.63$ & \\
& Other & 1.28 & $1.08 ; 1.51$ & \\
\hline Degree Type & MC & 1 & Reference & $<0.001$ \\
& MR & 1.52 & $1.25 ; 1.83$ & \\
& PhD & 1.25 & $1.03 ; 1.53$ & \\
\hline
\end{tabular}

$\mathrm{Cl}$ - Confidence Interval, MC - Masters by coursework and research report, MR - Masters by dissertation

\section{DISCUSSION}

While transformation is a complex process which can be categorised in different ways in the South African Higher Education sector (Du Preez, Simmonds, and Verhoef 2016), the present study researched transformation through aspects of redressing equity with respect to race, gender and access in a Faculty of Health Sciences (FHS). The critical shortage of health workers in the public sector in the country, requires urgent addressing (Couper and Hugo 2014; Labonté et al. 2015). Access is thus of the utmost importance in enabling an increase in the numbers of health workers and the transformation agenda of the country. While the current study has shown that access has occurred with respect to Black males in the Wits FHS, the same cannot be said for Black females.

The enrolment percentages of Black African first-time postgraduate students increased over the period 2008-2017, while White student enrolments decreased. A trend for Black African students to be male was noted. The total percentage of Chinese, Coloured and Indian (designated as "Other") students also increased slightly over the same period. Therefore, the increase in Black African postgraduate students did not occur at the expense of the latter group, who were in the past also considered as being from disadvantaged backgrounds.

In relation to gender, more female postgraduate students than males were enrolled for the first time for all degrees over the period 2008-2017. However, fewer Black African females than Black African males and White females were enrolled.

Regarding the degree type, Black Africans predominated in the Master's by coursework, while females predominated in all degree types. A significant increase of 18 per cent in females registered for the $\mathrm{PhD}$ occurred between 2008-2017.

The findings of the current study exhibit a marked increasing trend by approximately 7.5 per cent per year, of Wits FHS postgraduate students to be Black African. This trend is important in the context of transformation in South Africa. Since Black Africans form the majority $(80.9 \%)$ of the South African population (Stats SA Mid Year population estimates 2018), a predominance of Black Africans should be reflected in the demographic composition of students attaining postgraduate degrees in order to transform the health sciences and the health sector. The trend of Wits FHS postgraduate students to be Black African is mirrored at other higher education institutions in South Africa as Black African student enrolments have 
increased at masters level $(36 \%-46 \%)$ and at doctoral level $(25 \%-39 \%)$ between the years 2000 and 2007 (Soudien 2010). In the United States (US) an increase in enrolments of minorities (African American, American Indian and Hispanic) postgraduate students in Dental Education Programmes was similarly observed during the period 2000-2001 (Gates, Ganey, and Brown 2003).

Generally, females in South Africa have not been as well represented as males at postgraduate level in the past (Badat 2004, 2010; NACI 2009). Similarly in Malaysian universities, females are said to be under-represented at postgraduate level (Mokhtar 2012), and in selected universities in Nigeria, where more males (63\%) than females (37\%) were enrolled for postgraduate programmes in 2000 (Oredein 2002). While female enrolments in the Master of Medicine degree at the University of Cape Town, South Africa, have been increasing, male enrolments still predominated between 1999 and 2005 (Breier and Wildschut 2008). In contrast, studies in the United Kingdom and the US report that enrolment of females were equivalent to males at postgraduate level in the science, technology, engineering and mathematics (STEM) fields (Monroe et al. 2008; Leiden and Leuven 2012; Makunga 2017). Yet, the current study has found that females predominated as first-time enrolments for postgraduate studies in the Wits FHS during the period 2008-2017. This finding concurs with studies in Australia at the School of Public Health, Curtin University (Jancey and Burns 2013) and in South Africa in Psychology at the Wits School of Community Services (Mayekiso et al. 2013) where females predominate at postgraduate level. While Psychology and Public Health have traditionally been female dominated areas, inclusion of females in other fields of health sciences is warranted.

Female postgraduate students predominated in the Wits FHS as first-time enrolments for all degrees over the period under review. Moreover, the enrolments of females increased across all degrees whereas the males decreased. While the increase in female postgraduates in the Wits FHS is encouraging, the increment is dominated by White female students. A similar trend has been observed in the Psychology Department at Wits where the numbers of White females were higher than that of males at postgraduate level in the Wits School of Community Services (Mayekiso et al. 2013). It is an imperative to increase the enrolments of Black African female postgraduate students in South African higher education institutions as Black African females in particular, have been previously disadvantaged by apartheid and continue to be marginalised due to male chauvinism and rigid cultural practices (Ramohai 2019; Joubert and Guenther 2017). There appears to be a lacuna in the literature regarding Black African female postgraduate enrolments in South Africa, as males and females of this population group are generally jointly reported (Badat 2004; 2010; Soudien 2010; NACI 2009). Hence, an in depth analysis of the participation of Black African females at postgraduate level in all fields of health 
sciences is needed to highlight disparities in equity.

While the data in this study regarding gender could only be displayed in a binary format due to the way in which the data was originally captured, Wits has since changed its system to record gender self-identification. Pressure on higher education institutions to report to the Department of Higher Education on transformation, particularly race and gender (Hames 2007), resulted in "policy overload" (Kraak 2001) with a serious omission of "sexual orientation" from policy documents (Hames 2007). The "sexuality-inclusive transformation" was not as actively pursued in higher educational institutions as it is in civil society (Hames 2007), which may explain the delay in the introduction of categories into the Wits data. Protection against discrimination in sexual orientation was entrenched in the South African Constitution (Hatchard 1994), but there has been a disjuncture between what the constitution provides and the time taken to ensure its introduction into the community (Yacoob 2016). Transformation of documents in institutions to adequately capture the sexual self-identification is thus urgent.

Although an overall increase in enrolments of Black African postgraduate students was observed in this study, trend analysis indicated that the probability of a postgraduate student being Black African was less for the MR and $\mathrm{PhD}$ degrees. Therefore, the Wits FHS postgraduate pipeline may currently provide a limited pool for a diversified academic workforce as there are less Black Africans registering for those degrees in which research predominates i.e. in the Master's by research $(\mathrm{MR})$ and the Doctoral $(\mathrm{PhD})$ degrees. The shortage of Black African students at the MR level could be ascribed to Black African graduates preferring to find employment immediately after completing their undergraduate degrees, due to socio-economic challenges (Dell 2010). The MR degrees are also perceived as a conduit for basic science careers which are not regarded as positions which provide a substantial income compared with clinicians (Lander, Hanley, and Atkinson-Grosjean 2010). Similar obstacles are encountered by prospective Black African PhD students as the average South African PhD student is older, married or in a steady relationship and thus has to support their immediate family (Herman 2011). Moreover, postgraduate bursaries are meagre and cannot compete with salaries offered by companies which recruit Black African students in order to meet their employment equity targets (Herman 2011). Substantial postgraduate bursaries could entice graduates, particularly Black African graduates, to enrol for a MSc or $\mathrm{PhD}$ as the financial support could sustain them during a period when they are without employment or even only have partial employment. The current postgraduate bursaries offered mainly by the South African National Research Foundation (NRF) are not sufficient to support full-time postgraduate students. Black African students are often pressurised by their families to earn salaries immediately after completing their first degrees, owing to their poor backgrounds (Herman 2011; Mouton 2007) and the need 
to support an extended family. Thus, postgraduate bursaries which are comparable with market related salaries could assist in increasing the enrolment of Black African postgraduate students, especially at PhD level. Mouton (2007) recommended that the South African NRF and the South African National Treasury should be lobbied to increase funding for postgraduate degrees in order to provide substantive support for postgraduate students particularly full-time $\mathrm{PhD}$ students.

There is a preponderance of Black African students in the Master's by coursework (MC) degree. The MC degree at Wits includes degrees such as the Master of Public Health, Master of Dentistry, Master of Medicine, Master of Physiotherapy, Master of Occupational Therapy and Master of Nursing. Most students undertake these degrees while still employed (Benatar 2014; Essa 2011; Thomas and Thomas 2000). Therefore, there is less pressure on the students from their families regarding employment. However, there appears to be little interest from the MC degree graduates, particularly graduates in the medical specialities who form the largest group within this cohort, to enrol for a $\mathrm{PhD}$, as is evidenced by the shortage of clinician scientists in South Africa (Kramer, Veriava, and Pettifor 2015). Although Black African students predominate in the enrolments for the MC degrees, there are still disparities in gender as Black African males are in the majority. The predominance of Black African males at the MC level may continue to perpetuate disparities by creating a Black African male dominated postgraduate pipeline. Thus, the Wits FHS should ensure the recruitment of more females and particularly Black African females into the MC programme.

Enrolments at Wits FHS were compared to other low/middle income countries and countries with a majority of Black individuals in the population to place the study in an African and international context. The University of Dar es Salaam in Tanzania embarked on a successful recruitment initiative, targeting female students from secondary schools (Lihamba, Mwaipopo, and Shule 2006; Benjamin and Dunrong 2010) in order to increase female undergraduate students into fields such as chemistry, engineering, mathematics, medicine and physics (Lihamba, Mwaipopo, and Shule 2006; Benjamin and Dunrong 2010). A similar initiative could be adopted by the Wits FHS in order to attract graduates to enrol for postgraduate studies, particularly Black African females. The current lack of Black African females at masters and doctoral levels may further propagate under-representation of females in an already male dominated South African Health Sciences academic workforce (Coovadia et al. 2009; Thackwell et al. 2016). Therefore, it is fundamental to investigate barriers which may impact the enrolment of Black African females in postgraduate studies in large numbers, as Black African females constitute a major part of the South African population.

Barriers impacting Black African females entering into postgraduate studies may be 
multifactorial. Financial constraints including student debt, lack of mentorship, lack of support, selection criteria and long working hours have been reported as some of the major barriers impeding Black students (both females and males) from pursuing postgraduate studies locally (Herman 2011; Lessing and Schulze 2002) and internationally (Gates, Ganey, and Brown 2003; Lloyd, Phillips, and Aber 2004; Olaussen et al. 2017). In the US and Saudi Arabia, in fields such gastroenterology, surgery and urology, the lack of senior female role models is reported as being one of the critical factors for under-representation of females in health sciences, as females may prefer a female mentor due to "identification and understanding" (Hill et al. 2015; Alwazzan and Rees 2016; Mayer et al. 2017; Woodward et al. 2017). In addition, the differences in the nature of challenges faced by females from rural and urban Black African societies has been cited as a possible barrier in sub-Saharan Africa (Munene and Wambiya 2019). Rural females faced with socio-economic challenges and stringent cultural practices such as male chauvinism are less likely to access schooling than their urban counterparts from well developed areas with liberal cultural practices (Munene and Wambiya 2019; Chege and Arnot 2012; Mukudi 2017; Shabaya and Konadu-Agyemang 2004) and hence they do not enrol for higher degrees. Thus, socio-economic and cultural differences may be a barrier, preventing Black African female students from rural areas from enrolling in postgraduate studies at institutions such as Wits.

Interventions to tackle barriers impacting transformation must be undertaken as these barriers cause demographic disparities, not only in the postgraduate pipeline, but in the graduate cohort which will serve the public in the future. Thus an investigation of the barriers facing local postgraduate students may inform the nature of the interventions which need to be put in place for transformation to occur. Wits has undertaken a strategic plan with action areas such as student admissions, curriculum reform, promoting diverse and cosmopolitan residence life experience, institutional culture, and diversifying the Wits academy and language to accelerate the Wits transformation agenda (Wits University Senior Executive Team 2015). The Wits senior executive team's 2015 statement however accedes that the process of achieving equity redress at Wits has been slow (Wits University Senior Executive Team 2015).

Conflicts exist within the broader South African society which are also reflected in tensions within Institutional culture (SACHE 2016; Conco et al. 2020). Redressing equity in the postgraduate student population in health sciences and other Faculties in South Africa may result in transforming the institutional culture of higher education institutions, as many postgraduates continue in the system as academics, whether full-time or part-time. Kuh and Whitt (1988) maintain that institutional culture is based on "the collective, mutually supporting patterns of norms, values, practices, beliefs and assumptions that guide the behaviour of 
individuals and groups in an institution of higher learning and provide a frame of reference within which to interpret the meaning of events and actions on and off campus". Thus in order to change institutional culture in Higher Education institutions, the human resources of these institutions require transformation.

\section{LIMITATIONS OF THE STUDY}

Only South African students were considered in the current study, as transformation was regarded from the perspective of the South African agenda (DoE 1997). Transformation in relation to individuals with disabilities was not considered as this is beyond the scope of the present study. Future work should consider international students, individuals with disabilities and the lesbian, gay, bigenderual, transgender, queer, questioning, and intergender (LGBTQI) group (Farrow 2015).

\section{CONCLUSION}

Transformation of the Wits FHS postgraduate first-time enrolment student population has occurred in relation to population affinity and gender over the period 2008-2017. However, the increased trend per year of Black African students noted in this study was due to Black African male students and not Black African female students, although the number of female students rose over this period of time. The under-representation of Black African female first-time enrolments in the postgraduate pipeline is cause for concern in relation to building capacity for the future workforce. This study has shown the possibility of transforming the health sciences postgraduate population of the "minority" group. This is of importance to other countries struggling to support minority groups in the health sciences workforce of the future.

\section{ACKNOWLEDGEMENTS}

The authors wish to acknowledge the Wits Offices of the Registrar (Mrs Carol Crosley) and the Deputy Registrar (Mrs Nicoleen Potgieter) for permission to use data for the study. In addition, the Wits Business Intelligence Services (Mrs Harshila Dulabh) for providing the data. Dr Innocent Maposa and Professor Jonathan Levin are gratefully acknowledged for assistance with statistical analyses. This study is part of a $\mathrm{PhD}$ thesis registered at the University of the Witwatersrand.

\section{DECLARATIONS}

\section{Ethics approval}

Ethics approval to conduct this study was obtained from the University of the Witwatersrand's 
Human Research Ethics Committee (Medical) (Clearance certificate number: M180262).

\section{Availability of data and materials}

The data used in this study belongs to the University of the Witwatersrand and is not available for public sharing. However, permission was granted to the authors for use by the first author for $\mathrm{PhD}$ purposes.

\section{Competing interests}

The authors declare no competing interests.

\section{Funding}

No funding was acquired for this study. The authors declare that their salaries are paid by the Institution.

\section{REFERENCES}

Acosta, David, and Polly Olsen. 2006. "Meeting the Needs of Regional Minority Groups: The University of Washington's Programs to Increase the American Indian and Alaskan Native Physician Workforce." Academic Medicine. https://doi.org/10.1097/01.ACM.0000238047. 48977.05 .

Alwazzan, Lulu, and Charlotte E. Rees. 2016. "Women in Medical Education: Views and Experiences from the Kingdom of Saudi Arabia." Medical Education 50(8): 852-65. https://doi.org/ 10.1111/medu. 12988

Badat, Saleem. 2004. "Transforming South African Higher Education 1990-2003: Goals, Policy Initiatives and Critical Challenges and Issues." In National Policy and a Regional Response in South African Education, edited by N. Cloete, P. Pillay, S. Badat, and T. Moja, 1-50. Oxford University Press.

Badat, Saleem. 2010. "The Challenges of Transformation in Higher Education and Training Institutions in South Africa." Development Bank of South Africa. 2010. http://www.ru.ac.za/media/ rhodesuniversity/content/vc/documents/The Challenges of Transformation in Higher Eduaction and Training Institutions in South Africa.pdf.

Bazana, Sandiso, and Opelo P. Mogotsi. 2017. "Social Identities and Racial Integration in Historically White Universities: A Literature Review of the Experiences of Black Students." Transformation in Higher Education 2: 13. https://doi.org/10.4102/the.v2i0.25.

Benatar, Solly. 2014. "Professional Competence and Professional Misconduct in South Africa." South African Medical Journal. South African Medical Association. https://doi.org/10.7196/samj.8492.

Benjamin, Kapinga Bernadetha, and Bie Dunrong. 2010. "Increasing Access and Equity in Higher Education In Tanzania: A Case Study of University of Dar Es Salaam." The Social Sciences 5(3): 208-2012.

Breetzke, Gregory D., and David W. Hedding. 2018. "The Changing Demography of Academic Staff at Higher Education Institutions (HEIs) in South Africa." Higher Education 76(1): 145-61. https://doi.org/10.1007/s10734-017-0203-4.

Breier, Mignonne, and Angelique Wildschut. 2008. "ORIGINAL ARTICLES Changing Gender Profile of Medical Schools in South Africa." South African Medical Journal 98(7): 557-60.

Bunting, Ian. 2006. "The Higher Education Landscape Under Apartheid.” In Transformation in Higher Education: Global Pressures and Local Realities, 35-52. https://doi.org/10.1007/1-4020-4006- 
73.

Chege, Fatuma N., and Madeleine Arnot. 2012. "The Gender-Education-Poverty Nexus: Kenyan Youth's Perspective on Being Young, Gendered and Poor." Comparative Education 48(2): 195209. https://doi.org/10.1080/03050068.2011.608897.

Cloete, N., and T. Moja. 2005. "Transformation Tensions in Higher Education : Equity, Efficiency , and Deveiopment.” Social Research 72(3): 693-723.

Collinson, Mark A., Stephen M. Tollman, and Kathleen Kahn. 2007. "Migration, Settlement Change and Health in Post-Apartheid South Africa: Triangulating Health and Demographic Surveillance with National Census Data." Scandinavian Journal of Public Health 35(Suppl 69): 77-84. https://doi.org/10.1080/14034950701356401.

Conco, D., L. Baldwin-Ragaven, N. Christofides, E. Libhaber, L. Rispel, J. White, and B. Kramer. 2020. "Experiences of workplace bullying among academics in a health sciences faculty at a South African University." South African Medical Journal (SAMJ) (in press).

Coovadia, Hoosen, Rachel Jewkes, Peter Barron, David Sanders, and Diane McIntyre. 2009. "The Health and Health System of South Africa: Historical Roots of Current Public Health Challenges." The Lancet. https://doi.org/10.1016/S0140-6736(09)60951-X.

Couper, I. D., and J. F. M. Hugo. 2014. "Addressing the Shortage of Health Professionals in South Africa through the Development of a New Cadre of Health Worker: The Creation of Clinical Associates." Rural and Remote Health 14(3): 1-8.

Dell, Sharon. 2010. "South Africa: Decline in PhD Numbers a Major Problem." University World News. 2010. http://www.asocsa.org/news_articles/SharonDell_UniversityWorldNews_SOUTH_ AFRICA-Decline-in-PhD-numbers-a-major-problem-22August2010.pdf.

Department of Education. 1997. "White Paper 3: A Programme for Higher Education Transformation." Government Gazette. Pretoria: Department of Education. 1997. http://www.education.gov.za/ LinkClick.aspx?fileticket=jc97Bom2utk\%3D\&tabid=191\&mid=484.

Digby, Anne. 2013. "Black Doctors and Discrimination under South Africa's Apartheid Regime." Medical History 57(2): 269-90. https://doi.org/10.1017/mdh.2012.106.

DoE see Department of Education.

Du Preez, Petro, Shan Simmonds, and Anné Hendrik Verhoef. 2016. "Rethinking and Researching Transformation in Higher Education: A Meta-Study of South African Trends." Transformation in Higher Education 1(1): 7. https://doi.org/10.4102/the.v1i1.2.

Du Preez, Petro, Shan Simmonds, and Desiree Chetty. 2017. "Critical Transformation in Higher Education: Ethical Reflections on \#Mustfall Movements and Concomitant Gender-Based Violence." South African Journal of Higher Education 31(6): 96-112.

Essa, Ilhaam. 2011. "Reflecting on Some of the Challenges Facing Postgraduate Nursing Education in South Africa." Nurse Education Today 31(3): 253-58. https://doi.org/10.1016/j.nedt.2010.11.007.

Farrow, Alice. 2015. "Lactation Support and the LGBTQI Community." Journal of Human Lactation 31(1): 26-28. https://doi.org/10.1177/0890334414554928.

Francis, D., and C. Hemson. 2010. "Initiating Debate South African Journal of Higher Education: Issue on Transformation." South African Journal of Higher Education 24(6): 875-80.

Gates, Paul E., James H. Ganey, and Marc D. Brown. 2003. "Building the Minority Faculty Development Pipeline.” Journal of Dental Education 67(9): 1034-38.

Hames, Mary. 2007. "HamesSexualIdentity2007." Sexual Identity and Transformation at a South African University. SOCIAL DYNAMICS 33(1): 52-77.

Harris, Karen L. 2017. "BEE-Ing Chinese in South Africa: A Legal Historic Perspective." Fundamina 23(2): 1-20. https://doi.org/10.17159/2411-7870/2017/v23n2a1.

Hatchard, John. 1994. Statute Note the Constitution of the Republic of South Africa. Journal of African Law Vol. 38. https://doi.org/10.1017/S0021855300011499.

Herman, Chaya. 2011. “Expanding Doctoral Education in South Africa: Pipeline or Pipedream?” Higher 
Education Research and Development 30(4): 505-17. https://doi.org/10.1080/07294360. 2010.527928 .

Hill, Emily K., Rachel A. Blake, Jenna B. Emerson, Peter Svider, Jean Anderson Eloy, Christina Raker, Katina Robison, and Ashley Stuckey. 2015. "Gender Differences in Scholarly Productivity within Academic Gynecologic Oncology Departments." Obstetrics and Gynecology 126(6): 1279-84. https://doi.org/10.1097/AOG.0000000000001133.

Jancey, Jonine, and Sharyn Burns. 2013. "Institutional Factors and the Postgraduate Student Experience." Quality Assurance in Education 21(3): 311-22. https://doi.org/10.1108/QAE-Nov2011-0069.

Joubert, Marina, and Lars Guenther. 2017. "In the Footsteps of Einstein, Sagan and Barnard: Identifying South Africa's Most Visible Scientists." South African Journal of Science 113(11-12): 1-9. https://doi.org/10.17159/sajs.2017/20170033.

Keith, Stephen N., Robert M. Bell, August G. Swanson, and Albert P. Williams. 1985. "Effects of Affirmative Action in Medical Schools: A Study of the Class of 1975." New England Journal of Medicine. https://doi.org/10.1056/NEJM198512123132406.

Kraak, A. H. 2001. Policy ambiguity and slippage: Higher education under new state, 1994-2001. In Education in retrospect, ed. A. H. Kraak, and M. Young, 85-120. Pretoria: HSRC Publishers.

Kramer, Beverley, Yosuf Veriava, and John Pettifor. 2015. "Rising to the Challenge: Training the next Generation of Clinician Scientists for South Africa." African Journal of Health Professions Education 7(2): 153-54. https://doi.org/10.7196/AJHPE.671.

Kuh, George D., and Elizabeth J. Whitt. 1988. "The Invisible Tapestry: Culture in American Colleges and Universities." ASHE-ERIC Higher Education Report No. 1. Washington, D.C.: Association for the Study of Higher Education.

Labonté, Ronald, David Sanders, Thubelihle Mathole, Jonathan Crush, Abel Chikanda, Yoswa Dambisya, Vivien Runnels, et al. 2015. "Health Worker Migration from South Africa: Causes, Consequences and Policy Responses." Human Resources for Health 13(1): 1-16. https://doi.org/ 10.1186/s12960-015-0093-4.

Lander, Bryn, Gillian E. Hanley, and Janet Atkinson-Grosjean. 2010. "Clinician-Scientists in Canada: Barriers to Career Entry and Progress." PLOS ONE 5(10): 1-7. https://doi.org/10.1371/ journal.pone.0013168.

Lehohla, P. 2011. "Census 2011: Population Dynamics in South Africa." Statistics South Africa. http://www.statssa.gov.za/publications/Report-03-01-67/Report-03-01-672011.pdf.

Leiden, Universiteit, and K. U. Leuven. 2012. "Women, Research and Universities: Excellence without Gender Bias." League of European Research Universities. 2012. http://www.leru.org/files/ publications/LERU_Paper_Women_universities_and_research.pdf.

Lessing, A. C., and S. Schulze. 2002. "Postgraduate Supervision and Academic Support: Students' Perceptions." South African Journal of Higher Education 16(2): 139-49. https://doi.org/ 10.4314/sajhe.v16i2.25253.

Lihamba, Amandina, Rosemarie Mwaipopo, and Lucy Shule. 2006. "The Challenges of Affirmative Action in Tanzanian Higher Education Institutions: A Case Study of the University of Dar Es Salaam, Tanzania." Women's Studies International Forum 29(6): 581-91. https://doi.org/ 10.1016/j.wsif.2006.10.003.

Lloyd, Tom, Brenda R. Phillips, and Robert C. Aber. 2004. "Factors That Influence Doctors' Participation in Clinical Research." Medical Education 38(8): 848-51. https://doi.org/ 10.1111/j.1365-2929.2004.01895.x.

Luvalo, L. M. 2019. "Relationship between Transformtion and Institutional Culture." South African Journal of Higher Education 33(1): 184-99. https://doi.org/10.20853/33-1-2934.

Makunga, Nox. 2017. "Women Scientists Lag in Academic Publishing, and It Matters." The Conversation. 2017. https://theconversation.com/women-scientists-lag-in-academic-publishingand-it-matters-82521. 
Mayekiso, Tokozile, Francois Strydom, Vinitha Jithoo, and Lesley-Anne Katz. 2013. "Creating New Capacity through Postgraduate Selection." South African Journal of Psychology 34(4): 657-71. https://doi.org/10.1177/008124630403400409.

Mayer, Erik N., Sara M. Lenherr, Heidi A. Hanson, Terry C. Jessop, and William T. Lowrance. 2017. "Gender Differences in Publication Productivity Among Academic Urologists in the United States." Urology 103(May): 39-46. https://doi.org/10.1016/j.urology.2016.12.064.

Mokhtar, Mahani. 2012. "Intentions and Expectations of Female Phd Students in Engineering at One University in Malaysia." Procedia - Social and Behavioral Sciences 56(October): 204-212. https://doi.org/10.1016/j.sbspro.2012.09.647.

Monroe, Kristen, Saba Ozyurt, Ted Wrigley, and Amy Alexander. 2008. "Gender Equality in Academia: Bad News from the Trenches, and Some Possible Solutions." Perspectives on Politics 6(2): 21533. https://doi.org/10.1017/S1537592708080572.

Mostert-Wentzel, K., J. Frantz, and T. Van Rooijen. 2013. "Status of Undergraduate Community-Based and Public-Health Physiotherapy Education in South Africa." SA Journal of Physiotherapy 69(1): $1-10$.

Mouton, J. 2003. "South African Science in Transition." Science Technology \& Society 8(2): 235-60. https://doi.org/10.1177/097172180300800205.

Mouton, J. 2007. "Post-Graduate Studies in South Africa: Myths, Misconceptions and Challenges." South African Journal of Higher Education 21(1): 1078-90.

Mukudi. 2017. "Gender and Education in Africa." Comparative Education Review 46(2): 234. https://doi.org/10.2307/3542197.

Munene, Ishmael I., and Paschal Wambiya. 2019. "Bridging the Gender Gap through Gender Difference: Aiding Patriarchy in South Sudan Education Reconstruction." Africa Education Review 16(5): 86-101. https://doi.org/10.1080/18146627.2018.1429052.

Murray, B. K. 2007. "Wits as an 'Open' University 1939-1959: Black Admissions to the University of the Witwatersrand." Journal of Southern African Studies 16(4): 649-76. https://doi.org/ 10.1080/03057079008708255.

NACI. 2009. "Facing the Facts: Women's Participation in Science, Engineering and Technology 2009." Report Commissioned by the Science, Engineering and Technology for Women (SET4W) SubCommittee of the National Advisory Council. 2009. http://www.naci.org.za/wpcontent/uploads/Facing-the-Facts-Womens-Participation-in-Science-Engineering-andTechnology-2009.pdf.

Nelson, Alan. 2002. "Unequal Treatment: Confronting Racial and Ethnic Disparities in Health Care." Journal of the National Medical Association 94(8): 666-68. https://doi.org/10.1001/ jama.290.18.2487-b.

Noonan, Allan, Ian Lindong, and Vijai N. Jaitley. 2013. "The Role of Historically Black Colleges and Universities in Training the Health Care Workforce." American Journal of Public Health 103(3): 412-415. https://doi.org/10.2105/AJPH.2012.300726.

Norris, B. D. 2001. "Transformation, Diversity and Organisational Change within Institutions of Higher Education." South African Journal of Education 21(4): 219-21.

Olaussen, Alexander, Paul A. Jennings, Gerard O'Reilly, Biswadev Mitra, and Peter A. Cameron. 2017. "Barriers to Conducting Research: A Survey of Trainees in Emergency Medicine." EMA Emergency Medicine Australasia 29(2): 204-9. https://doi.org/10.1111/1742-6723.12734.

Oredein, Afolakemi Olasumbo. 2002. "Postgraduate Students' Supervision and Training in Nigerian Tertiary Institutions: A Comparative Study." Towards Quality in African Higher Education. https://www.researchgate.net/profile/Afolakemi_Oredein/publication/237434324_Postgraduate Students'Supervision_and_Training_in_Nigerian_Tertiary_Institutions_A_Comparative_Study /links/568e497608aef987e56798bf.pdf.

Ramohai, Juliet. 2019. “A Black Woman's Perspective on Understanding Transformation and Diversity in South African Higher Education.” Transformation in Higher Education 4: 1-10. https://doi.org/ 
10.4102/the.v4i0.58.

Ramrathan, Labby. 2016. "Beyond Counting the Numbers: Shifting Higher Education Transformation into Curriculum Spaces." Transformation in Higher Education 1(1): 1-8. https://doi.org/ 10.4102/the.v1i1.6.

Robus, Donovan, and Catriona Macleod. 2006. "White Excellence and Black Failure': The Reproduction of Racialised Higher Education in Everyday Talk." South African Journal of Psychology 36(3): 463-80. https://doi.org/10.1177/008124630603600303.

SACHE. 2016. "South African Higher Education Reviewed; Two Decades of Democracy." Council on Higher Education. https://doi.org/10.1080/02642060701453288.

Seabi, Joseph, Jaishika Seedat, Katijah Khoza-Shangase, and Lakeasha Sullivan. 2014. "Experiences of University Students Regarding Transformation in South Africa." International Journal of Educational Management 28(1): 66-81. https://doi.org/http://dx.doi.org/10.1108/MRR-09-20150216.

Shabaya, Judith, and Kwadwo Konadu-Agyemang. 2004. "Unequal Access, Unequal Participation: Some Spatial and Socio-economic Dimensions of the Gender Gap in Education in Africa with Special Reference to Ghana, Zimbabwe and Kenya." Compare 34(4): 395-424. https://doi.org/ 10.1080/0305792042000294805.

Shung-King, Maylene, Lucy Gilson, Chinyere Mbachu, Sassy Molyneux, Kelly W. Muraya, Nkoli Uguru, and Veloshnee Govender. 2018. "Leadership Experiences and Practices of South African Health Managers: What Is the Influence of Gender? A Qualitative, Exploratory Study." International Journal for Equity in Health. https://doi.org/10.1186/s12939-018-0859-0.

Smedley, Brian D., Adrienne Y. Stith, and Alan R. Nelson. 2003. Unequal Treatment: Confronting Racial and Ethnic Disparities in Health Care (with CD). Unequal Treatment: Confronting Racial and Ethnic Disparities in Health Care (with CD). https://doi.org/10.17226/12875.

Smith, Sonya G., Phyllis A. Nsiah-Kumi, Pamela R. Jones, and Rubens J. Pamies. 2009. "Pipeline Programs in the Health Professions, Part 1: Preserving Diversity and Reducing Health Disparities." Journal of the National Medical Association. https://doi.org/10.1016/S00279684(15)31030-0.

Soudien, C. 2009. "Critical Reflection on the Report of the Ministerial Committee on Transformation, Social Cohesion and the Elimination of Discrimination in Public Higher Education." Perspectives in Education. 2009. https://www.gov.za/report-ministerial-committee-transformation-and-socialcohesion-and-elimination-discrimination.

Stats SA Mid Year population estimates. 2018. "South African Stats SA Mid-Year Population Estimates 2018.”2018. www.statssa.gov.zainfo@statssa.gov.za.

Sullivan, Louis W. 2004. "Missing Persons: Minorities in the Health Professions, a Report of the Sullivan Commission on Diversity in the Healthcare Workforce." Diversity. 2004. https://drum.lib.umd.edu/bitstream/handle/1903/22267/Sullivan_Final_Report_000.pdf?sequenc $\mathrm{e}=1$ \&isAllowed $=\mathrm{y}$.

Thackwell, Nicola, Leslie Swartz, Sipho Dlamini, Lebogang Phahladira, Rudzani Muloiwa, and Bonginkosi Chiliza. 2016. "Race Trouble: Experiences of Black Medical Specialist Trainees in South Africa." BMC International Health and Human Rights 16(1): 1-6. https://doi.org/ 10.1186/s12914-016-0108-9.

Thomas, M., and M. J. Thomas. 2000. "A Discussion of Some Critical Aspects in Planning of Community Based Rehabilitation." Asia Pacific Disability Rehabilitation Journal. 2000. http://search.ebscohost.com/login.aspx?direct=true\&db=rzh\&AN=2002015856\&site=ehost-live.

Times Higher Education Ranking. 2019. "Best Universities for Medicine 2019." Times Higher Education. 2019. https://www.timeshighereducation.com/student/best-universities/bestuniversities-medicine.

Tobias, Phillip V. 2005. "Apartheid and Medical Education: The Training of Black Doctors in South Africa." International Journal of Health Services 13(1): 131-53. https://doi.org/10.2190/fceq- 
9w71-wd9p-5cp9.

Turok, Ivan, and Jacqueline Borel-Saladin. 2014. "Is Urbanisation in South Africa on a Sustainable Trajectory?" Development Southern Africa 31(5): 675-91. https://doi.org/10.1080/ 0376835X.2014.937524.

University of the Witwatersrand Transformation Transformation Office. 2017. "The Operation of Transformation Committees at Faculty and Support Department Level." University of the Witwatersrand Transformation Guidelines. University of the Witwatersrand. https://www.wits.ac.za/transformationoffice/.

Van Niekerk, A. 1998. "Values, Transformation and Social Work in South Africa." Social Work 34(1): $60-70$.

Volmink, John D. 2008. "Education for Learning to Live Together: What Can We Learn from the South African Experience?" European Journal of Education 43(2): 189-96. https://doi.org/10.1111/ j.1465-3435.2008.00346.x.

Waghid, Yusef. 2002. "Knowledge Production and Higher Education Transformation in South Africa: Towards Reflexivity in University Teaching, Research and Community Service." Higher Education 43(4): 457-488. https://doi.org/10.1023/A:1015211718131.

Westring, Alyssa Friede, Rebecca M. Speck, Mary Dupuis Sammel, Patricia Scott, Lucy Wolf Tuton, Jeane Ann Grisso, and Stephanie Abbuhl. 2012. "A Culture Conducive to Women's Academic Success: Development of a Measure." Academic Medicine. https://doi.org/10.1097/ ACM.0b013e31826dbfd1.

Wing, Adrien Katherine, and Eunice P. De Carvalho. 1995. "Black South African Women: Toward Equal Rights." Harvard Human Rights Journal 8: 57-100.

Wits University Senior Executive Team. 2015. "Wits University Executive Statement on Accelerating Transformation.” Wits University. Johannesburg: Wits University. 2015. http://blogs.wits.ac.za/ $\mathrm{vc} / \mathrm{wp}$-content/uploads/sites/3/2015/10/Wits-University-Executive-Statement-on-AcceleratingTransformation2.pdf.

Woodward, Zibing, Zaida Rodriguez, Janice H. Jou, Kian Keyashian, Yiyi Chen, Charles R. Thomas, Grace H. Elta, and Sharlene L. D’Souza. 2017. “Gender Disparities in Gastroenterology Fellowship Director Positions in the United States." Gastrointestinal Endoscopy 86(4): 595-99. https://doi.org/10.1016/j.gie.2017.01.019.

Yacoob, Zak. 2016. "Sex and Gender Transformation in Africa." South African Journal of Science 112(11-12): 11-12. https://doi.org/10.17159/sajs.2016/a0188. 